\title{
Reversible Blockage of Neurite Development and Growth Cone Formation in Neuronal Cultures of a Temperature-Sensitive Mutant of Drosophila
}

\author{
Yun-Taik Kim and Chun-Fang Wu \\ Department of Biology, University of lowa, lowa City, lowa 52242
}

\begin{abstract}
It has been suggested that the membrane recycling process in the Drosophila mutant shibire ${ }^{\text {ts } 1}$ (shist) is reversibly blocked at restrictive temperature $\left(>29^{\circ} \mathrm{C}\right)$ in various cell types, including neurons, as a result of enhanced vesicle fusion and disrupted membrane pinch-off (Poodry and Edgar, 1979; Koenig et al., 1983; Kosaka and Ikeda, 1983a, b). We analyzed the neuronal development of shirst cells at the singlecell level by using dissociated larval CNS culture. Compared to normal cultures, there was a substantial reduction in neuronal adhesion to the substratum and a retardation of growth cone formation in shist cultures at $30^{\circ} \mathrm{C}$. Time-lapse studies showed that neurite initiation and elongation in shist cultures were suppressed at the restrictive temperature. Differentiated $s h^{i s} 1$ neurons exhibited accelerated reabsorption and retarded arborization of neurites at $30^{\circ} \mathrm{C}$. The above processes were reversible since normal outgrowth was restored when the temperature was lowered. These findings provide a new line of evidence that growth cone activity determines neurite initiation, elongation, and branching. Furthermore, if the primary defect of the $s$ irs $^{\text {1 }}$ mutation indeed resides in a membrane recycling mechanism common to different cell types, our results would also lend strong support to the notion that membrane recycling is cruclal in the regulation of neuronal membrane adhesion and growth cone activity.
\end{abstract}

The development of neurons and the functional organization of nervous systems are dependent upon macromolecules encoded by genes. By altering relevant genes, mutants with specific biochemical, anatomical, or behavioral abnormalities can be produced. This approach has been effectively employed to probe the development and function of the nervous system of Drosophila melanogaster (Benzer, 1973; Hall, 1982).

Several temperature-sensitive paralytic mutants of Drosophila have been isolated (Grigliatti et al., 1973; Siddiqi and Benzer, 1976; Wu et al., 1978; Singh and Siddiqi, 1981; Kulkarni and Padhye, 1982; Ganetzky and Wu, 1985). Among them, the sexlinked recessive mutant shibire ${ }^{t s l}\left(s h i^{t s l}\right)$ becomes paralyzed above the restrictive temperature $\left(29^{\circ} \mathrm{C}\right)$ and gradually recovers when the temperature is lowered (Grigliatti et al., 1973).

\footnotetext{
Received Oct. 27, 1986; revised May 1, 1987; accepted May 5, 1987.

We are grateful to Dr. J. J.-C. Lin for his contributions to the biochemical studies and helpful discussions. We also thank Drs. J. Denburg, M. Gorczyca, P. G. Haydon, S. B. Kater, and A. Komatsu, and Mr. M. G. Burg for comments on the manuscript. This work was supported by NIH Grants NS00675, NS15350, and NS18500 to C.-F. Wu.

Correspondence should be addressed to Dr. Chun-Fang Wu at the above address. Copyright (C) 1987 Society for Neuroscience $0270-6474 / 87 / 103245-11 \$ 02.00 / 0$
}

Previous studies indicate that paralysis in $s h i^{i s I}$ flies is caused by a temperature-dependent disruption in synaptic transmission. At the neuromuscular junction, a progressive diminution of the excitatory junctional potentials (Ikeda et al., 1976; Siddiqi and Benzer, 1976; Koenig et al., 1983) and a reduction in the frequency of spontaneous miniature excitatory junctional potentials (Koenig et al., 1983) occurs as the temperature is raised above $29^{\circ} \mathrm{C}$. These effects appear to be presynaptic, since $s h i^{i s I}$ muscle fibers respond normally at high temperature to direct electrical stimulation (Ikeda et al., 1976) and to the putative transmitter L-glutamate (Koenig and Ikeda, 1983). Moreover, studies of $s h i^{i s I}$ genetic mosaics showed that the transmission block occurs when the motor neuron is mutant regardless of the genotypes of the muscle (Koenig and Ikeda, 1983). Defects in $s h i^{i s t}$ flies are not limited just to the neuromuscular junction. Synaptic transmission between photoreceptors and laminar neurons may be blocked at high temperature, as suggested by electroretinogram analysis (Kelly and Suzuki, 1974). In addition, radiochemical studies have indicated that the storage and release of the neurotransmitter $\mathrm{ACh}$ at high temperature are altered in the CNS of $s h i^{t s i}$ larvae (Wu et al., 1983a).

Changes in membrane fusion and retrieval that could explain the disruption in synaptic transmission have been observed. When $s h i^{t s I}$ flies are held at or above $29^{\circ} \mathrm{C}$ for over $2.5 \mathrm{~min}$, a decrease in the number of synaptic vesicles and a corresponding increase in the number of cisternae or large vesicles can be found in presynaptic terminals of neuromuscular junctions of tibial muscles (Poodry and Edgar, 1979) and dorsal longitudinal flight muscles (Koenig et al., 1983). Synaptic vesicles reappear upon returning to room temperature. 'Temperature-induced vesicle fusion in the sarcolemma of indirect flight muscles has also been obscrved in $s h i^{t s t}$ flies (Costello and Salkoff, 1986). Evidence for a defective membrane retrieval mechanism at high temperature was provided by Kosaka and Ikeda (1983a), who showed an accumulation of many pitlike structures in the plasma membrane at presynaptic terminals of various kinds of motor, sensory, and central neurons. In fact, a reversible blockage of endocytosis, presumably due to disrupted membrane pinch-off, has been directly demonstrated in the shist garland cells (Kosaka and Ikeda, 1983b).

This temperature-induced membrane defect appears to disrupt the development of different cell types, including myocytes in embryonic culture (Buzin et al., 1978), and flight muscles (Costello and Salkoff, 1983) and imaginal disk-derived tissues (Poodry et al., 1973; Suzuki, 1974) in pupae. It has been reported that high-temperature treatments during metamorphosis alter the development of the giant fiber pathway in $s h i^{i s t}$ flies (Hum- 
mon and Costello, 1984; 1987). This raises the possibility that the $s h i^{i s 1}$ mutation may directly affect growth cone activity and ncurite cxtcnsion. In this study, we confirmed this possibility by utilizing the culture system of larval CNS neurons (Wu et al., 1983b). We have extensively investigated, in time-lapse experiments, the effects of high-temperature treatments on neurite initiation, elongation, and arborization in $s h i^{i s l}$ neurons at the single-cell level. The changes were correlated to growth cone formation and cell membrane adhesion properties. The role of membrane recycling in neuronal morphological development is discussed and the abnormal membrane fusion and retrieval process found in various $s h i^{i s t}$ cell types are evaluated as the mechanism underlying the altered neuronal morphology reported here. A preliminary account of some of the results reported here has appeared previously (Kim and Wu, 1986).

\section{Materials and Methods}

Animal stocks. The wild-type strain Canton-S and the mutant allele $s h i^{\text {sl }}$ of Drosophila melanogaster raised at room temperature were used. Among the available alleles of the $s h i^{i s}$ locus, $s h i^{i s i}$ has been studied most extensively (Grigliatti et al., 1973; Poodry et al., 1973; Suzuki, 1974; Kosaka and Ikeda, 1983a, b). A different allele shis ${ }^{5139}$ (Siddiqi and Benzer, 1976) was also examined.

CNS cell culture. A revised Schneider's Drosophila culture medium (Schneider and Blumenthal, 1978) containing 10\% heat-inactivated fetal bovine serum, penicillin ( $50 \mathrm{units} / \mathrm{ml})$, and streptomycin sulfate $(50 \mu \mathrm{g} /$ $\mathrm{ml}$ ) was used. Dissociated larval neurons can be grown in this medium for several weeks (Wu et al., 1983b). All the above solutions and chemicals were obtained from GIBCO (Grand Island Biological Co., Grand Island, NY).

Preparation of the primary cultures of dissociated CNS cells was essentially the same as that reported previously (Wu et al., 1983b). Brains and ganglia dissected from mature third instar larvae were cut into small fragments in culture medium and were incubated for $40 \mathrm{~min}$ to $1 \mathrm{hr}$ at room temperature $\left(22 \pm 1^{\circ} \mathrm{C}\right.$, permissive temperature) in $\mathrm{Ca}^{2+}$ - and $\mathrm{Mg}^{2+}$-free solution $(137 \mathrm{~mm} \mathrm{NaCl}, 2.7 \mathrm{~mm} \mathrm{KCl}, 0.36 \mathrm{~mm}$ $\mathrm{NaH}_{2} \mathrm{PO}_{4} \cdot \mathrm{H}_{2} \mathrm{O}, 11.9 \mathrm{~mm} \mathrm{NaHCO}, 5.6 \mathrm{~mm}$ glucose; see Schneider and Blumenthal, 1978 ) containing $0.33-0.50 \mathrm{mg} / \mathrm{ml}$ collagenase (Type $\mathrm{I}$, Sigma Chemical Co., St. Louis, MO). The tissue fragments were then dissociated into single cells by repeated passage through the small opening (100-200 $\mu \mathrm{m})$ of siliconized glass pipettes with fire-polished tips. Fifty to $100 \mu \mathrm{l}$ of cell suspension were plated onto $35 \mathrm{~mm}$ tissue culture dishes (Corning) or onto round glass coverslips (12-15 $\mathrm{mm}$ in diameter) kept in plastic dishes. The plating surface of tissue culture dishes or coverslips was precoated with poly(L-lysine) hydrobromide $\left(M_{W}>30,000\right.$, Sigma Chemical Co. ) in $0.2 \mathrm{M}$ Tris buffer $(1 \mathrm{mg} / \mathrm{ml}), \mathrm{pH} 8.4$ (Letourneau, 1975; Banker and Cowan, 1977). As an exception, plain glass coverslips were used in the phase-contrast microscopy of growth cones (Fig. 1, Table 2). Cells showed increased growth cone activities on this less adhesive substratum.

To prevent evaporation of the culture medium, the dishes were kept in a humidified chamber. Cultures were routinely incubated at $22 \pm$ $1{ }^{\circ} \mathrm{C}$ (permissive temperature). For temperature shifts, an incubator at $30 \pm 1{ }^{\circ} \mathrm{C}$ (restrictive temperature) was used. Culture ages are given below as hours or days after plating.

Dissociated neurons were plated at densities ranging from 100 to 400 cells $/ \mathrm{mm}^{2}$. After $2-3 \mathrm{hr}$ incubation, more than $50 \%$ of the dissociated cells initiated axonlike processes. At this stage, dissociated cells could be classified into 3 categories by their sizes and morphology as previously described (Wu et al., 1983b). Type I cells were large $(>8 \mu \mathrm{m})$ neuroblasts, usually accompanied by smaller daughter cells; type II cells were relatively small $(2-3 \mu \mathrm{m})$ monopolar cells that frequently had long $(>20 \mu \mathrm{m})$ neurites; type III cells were oval or spindle-shaped cells of intermediate size $(4-10 \mu \mathrm{m})$ and usually had thick and short processes. Type I cells were rare ( $<5 \%$ of the total population) and were excluded from this study. In the following experiments, the observations on type II and III cells were combined because consistent results were obtained from them.

Scoring cultures for neurite growth. For the time-lapse study of neurite growth, cultured neurons were scored with phase-contrast optics (Nikon Diaphot inverted microscope with a $40 \times, 0.55$ N.A. objective) at the ages of $3 \mathrm{hr}$ and of $1,2,3$, and in some cases $4 \mathrm{~d}$. Previous studies showed that dissociated larval neurons enter a morphological steadystate after $3 \mathrm{~d}$ in culture, coincident with the duration of pupation (Wu et al., 1983b).

To examine the effects of high temperature, shist cultures were observed immediately before and after $24 \mathrm{hr}$ incubation at $30^{\circ} \mathrm{C}$. Cultures of $2 \mathrm{hr}$ and $1 \mathrm{~d}$ of age were treated in this manner. The same temperatureshift experiments were carried out on normal cultures. For each experiment, both control and experimental cultures were prepared and observed at the same time.

The lengths of primary neurites of single cells were directly measured with a reticle in the eyepiece of the microscope or determined on photographs. Neurites shorter than $4 \mu \mathrm{m}$ in length were excluded from analysis because they cannot be reliably distinguished from irregularities in cell shape. To simplify the measurement, only the longest primary neurites were recorded for bipolar or multipolar cells.

To ensure that the same cells were recorded during the time-lapse studies, fixed areas were identified with markings ( 2 cross lines) on the bottom of the tissue culture dishes. For each single culture, an area of $0.65-1.45 \mathrm{~mm}^{2}$ was examined.

In a later phase of this study, a video camera system with contrast enhance circuit (Hamamatsu Photonics C2400-07) was used in conjunction with phase-contrast optics (Zeiss IM-35 with a $100 \times, 1.3$ N.A. objective). The finer details of growth cone morphology were resolved on the video monitor (Fig. 1).

Scanning electron microscopy. Specimens for scanning electron microscopy (SEM) were prepared based on the methods described previously (Wolosewick and Porter, 1979). Dissociated cells were plated onto the poly(L-lysine)-coated round glass coverslips (12 $\mathrm{mm}$ in diameter). The coverslips with cells were washed briefly in Drosophila saline (Wu et al., 1983b) to remove cell debris. Cells were fixed with $1 \%$ glutaraldehyde in Drosophila saline for $10 \mathrm{~min}$.

To observe the effects of high temperature on neurite arborization and growth cone morphology, cultures were kept at $22^{\circ} \mathrm{C}$ for at least 16 $\mathrm{hr}$ after plating and then shifted to $30^{\circ} \mathrm{C}$ for $4-8 \mathrm{hr}$ prior to fixation, as specified in different experiments. Solutions used in wash and fixation procedures were prewarmed to $30^{\circ} \mathrm{C}$ before application.

Following fixation and dehydration through an alcohol series, cultures were immersed in hexamethyldisilazane (HMDS, Sigma Chemical Co.) for $5 \mathrm{~min}$ and air-dried in a ventilation hood at room temperature, as previously described by Nation (1983). The specimens were sputtercoated with gold and palladium and observed with a scanning electron microscope (JEOL JSM 35C) at an accelerating voltage of 13 or $14 \mathrm{kV}$.

In the SEM experiments, nerve terminals with flattened veillike lamellipodia and/or filopodia were defined as growth cones. Fine processes projecting from the lamellipodia were taken as filopodia. In some cases, lamellipodia degenerated to club shapes, and the fine projections remaining at these structures were considered as filopodia. Since the diameter of filopodia is rather constant at about $0.15 \mu \mathrm{m}$ (Bray, 1973b; Landis, 1983), filopodia could be distinguished from nonfilopidial processes by their thinner diameters as well as their positions.

\section{Results}

Qualitative observations of individual $\mathrm{shi}^{\text {ts1 }}$ neurons

At room temperature, the morphology of $s h i^{t s I}$ neurons was apparently normal. Neurite outgrowth and growth cone activity were readily observed (Fig. 1). Neuroblasts underwent asymmetrical division to give rise to more daughter cells (Fig. 1).

This culture system contains neurons of heterogeneous developmental stages because the larval CNS undergoes vigorous development before entering metamorphosis (White and Kan$\mathrm{kcl}, 1978)$. Tempcraturc-scnsitive changes in $s h i^{t^{\prime}}$ cultures may reflect the ensemble effect of neurite initiation, reabsorption, elongation, and retraction, as schematically illustrated in Figure 2. In order to analyze each of these processes, time-lapse observations on individual neurons were necessary.

Figures 3 and 4 show tracings of representative populations of single cells in normal and $s h i^{t s I}$ cultures subject to temperature shifts at the ages of 0 and $1 \mathrm{~d}$. During the experiments, single neurons remained at fixed positions, and their neurites main- 


\section{normal}
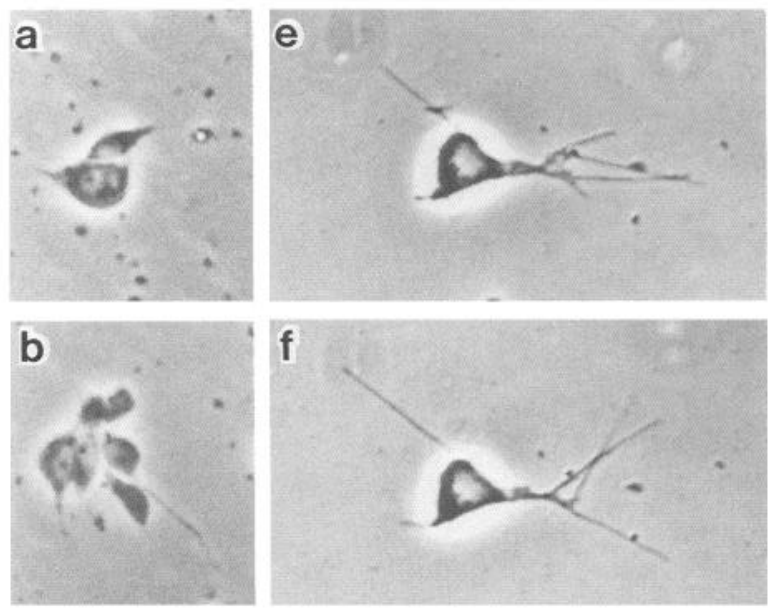

\section{shitsl}
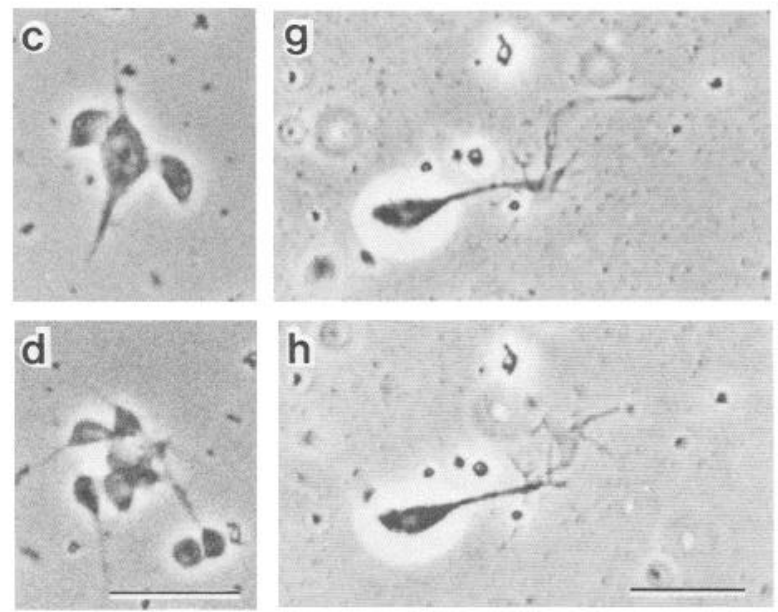

Figure 1. Neurons in dissociated cell cultures from normal and $s h i^{i s l}$ larval CNS at $22^{\circ} \mathrm{C}$. Asymmetric divisions of neuroblasts and initiation of neurite outgrowth of their daughter cells were much the same in normal $(a, b)$ and $\operatorname{shi}^{i s l}(c, d)$ cultures. Panels $a$ and $b$, and $c$ and $d$ are sequential records (phase-contrast micrographs) taken $1 \mathrm{~d}$ apart. Active movements of filopodia and lamellipodia were observed in both normal $(e, f)$ and $\operatorname{shi}^{i s t}(g, h)$ growth cones. Panels $e$ and $f$, and $g$ and $h$ are sequential records (video contrast-enhanced micrographs) taken $10 \mathrm{sec}$ apart. During the observation periods no substantial migration of single neurons was observed. In this and the following figures, time-lapse observations on the same cells were ensured by the marking technique described in Materials and Methods. Scale bar, $10 \mu \mathrm{m}$.

tained roughly constant directions of growth (Figs. 3 and 4). The overall pattern of neurite outgrowth in $s h l^{i s l}$ cultures was evidently altered by high temperature (compare Figs. $3 ; 4, c, d$ ).

Following plating, incubation at $30^{\circ} \mathrm{C}$ for $24 \mathrm{hr}$ suppressed neurite initiation and increased neurite reabsorption in $s h i^{i s l}$ neurons (Fig. 3). In contrast, the neurite outgrowth in normal cultures was not interrupted under the same condition (Fig. 3). This temperature-induced neurite retraction also occurred in $s h i^{i s t}$ cultures of older ages. As compared to normal neurons, temperature shifts to $30^{\circ} \mathrm{C}$ during the second day of incubation caused neurite retraction in most (>85\%) shist neurons (Fig. 4, compare $a$ and $c$ ). However, in $s h i^{i s l}$ cultures maintained at room

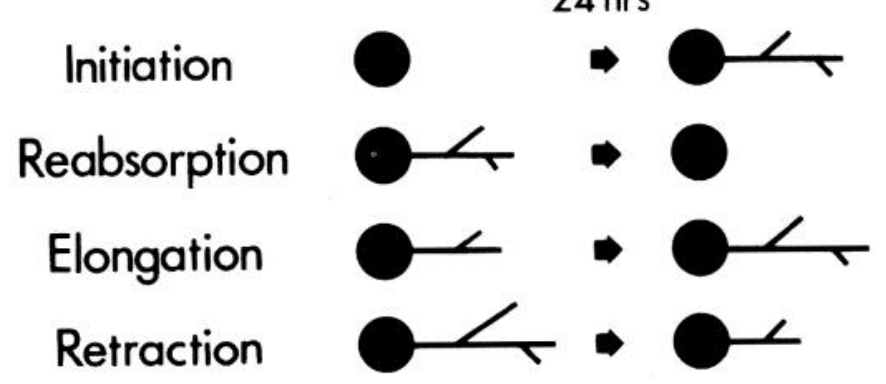

Figure 2. Schematic illustration of neurite initiation, reabsorption, elongation, and retraction.

temperature, the majority of the cells had grown continuously, as had those in normal cultures (Fig. 4, b, d).

Similar results were obtained from the strain $s h i^{S T 139}$, an independent isolate in a different genetic background (Siddiqi and Benzer, 1976). Therefore, the observed changes are not likely due to mutations at other sites.

Neurite retraction and reabsorption in $s h i^{i s i l}$ neurons at $30^{\circ} \mathrm{C}$ can be separated from the cell death process. Degenerating and dying neurons generally become spherical and finally detach from the culture dish (Wu et al., 1983b). At $30^{\circ} \mathrm{C}$, neurite retraction and reabsorption of $s i^{i s l}$ neurons occurred within hours, whereas the cell bodies retained their initial morphology for days and could reinitiate neurite outgrowth when the temperature was lowered (about 80,50 , and $5 \%$ for 1, 2, and $3 \mathrm{~d}$ treatments, respectively). Therefore, cell death may not be a significant factor causing neurite retraction and reabsorption within the time periods reported here.

\section{Quantitative measurements}

By tracing individual cells at successive time intervals, the morphological changes of $s h i^{\text {sst }}$ neurons induced by temperature shifts can be monitored at a more refined level. Cellular responses such as initiation, elongation, retraction, and reabsorption of neurites (Fig. 2), and elaboration of branching pattern were quantitatively analyzed.

Neurite initiation. Newly seeded cells that were devoid of neurites but subsequently initiated neurite outgrowth were studied first. In $s h i^{i s l}$ cultures, neurite initiation was suppressed during high-temperature treatments (Fig. 5, $d, e$ ) as compared with untreated cultures (Fig. $5 f$ ). The suppression by high temperature is at least partially reversible. In both first-day (Fig. $5 d$ ) and second-day (Fig. $5 e$ ) treated cultures, neurite initiation showed a rebound following the downshifts of temperature. In contrast, neurite initiation in normal cultures was not inhibited or was even slightly accelerated during the $30^{\circ} \mathrm{C}$ incubation (Fig. 5 , compare $a$ and $b$ to $c$ ).

Neurite reabsorption. Cells with neurites in shist cultures exhibited an increased occurrence of complete neurite reabsorption at $30^{\circ} \mathrm{C}$. They either reinitiated neurite outgrowth upon returning to low temperature or eventually detached from the substratum. Figure 6 compares the cells that reabsorbed their neurites in $s h i^{i s t}$ and normal cultures within the $3 \mathrm{~d}$ observation period. In $s h i^{i s l}$ cultures, the frequency of neuritic reabsorption was markedly increased by high-temperature treatment during either the first- or second-day incubation, which was not observed in normal cultures (Fig. 6).

To examine whether neurite reabsorption in $s h i^{i s l}$ neurons 
normal

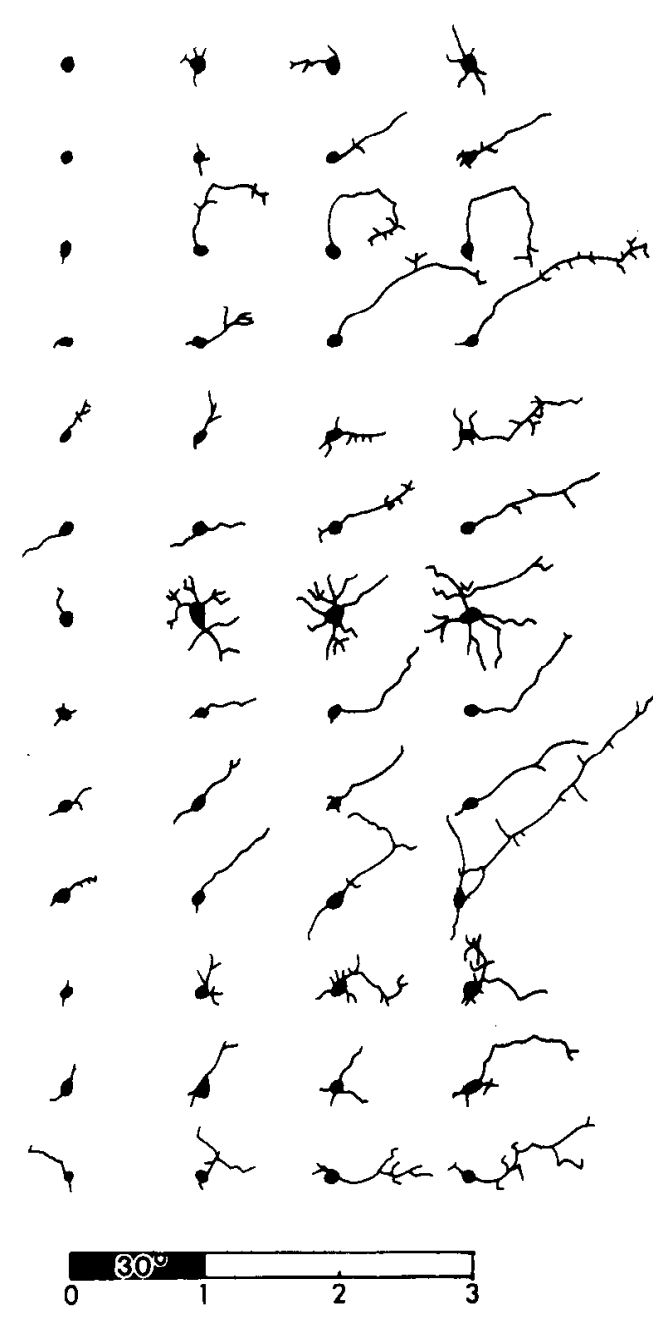

$s h i^{i s l}$

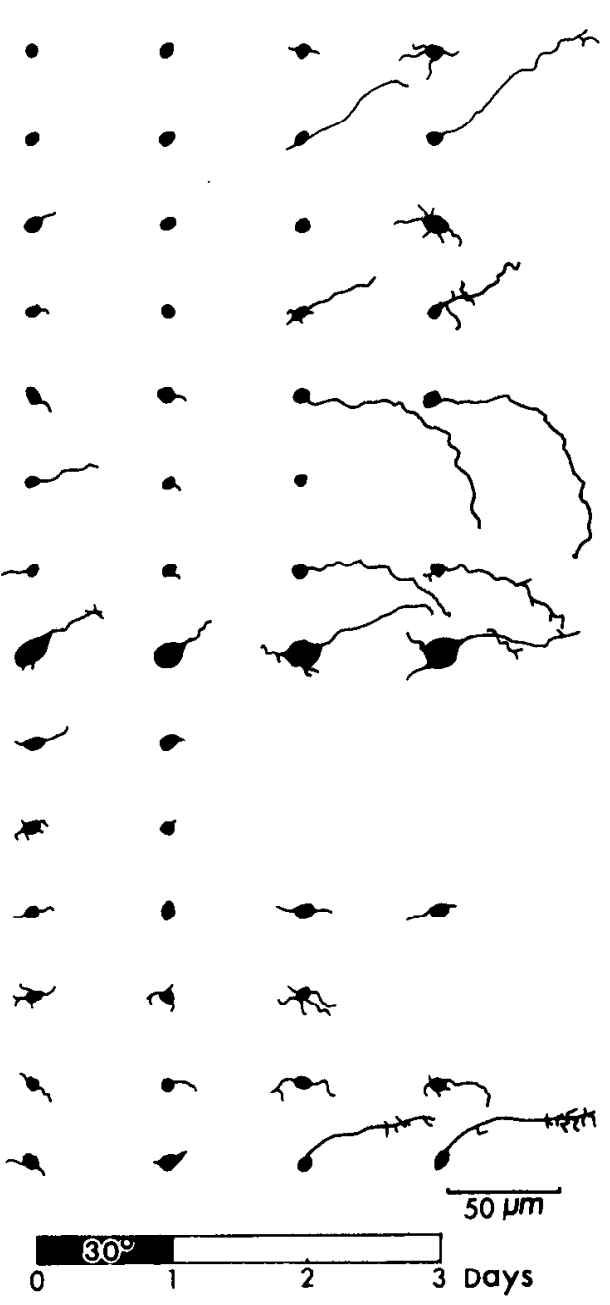

Figure 3. Effects of high-temperature treatment during the first day of incubation on normal and $s h i^{i s t}$ neurons. In this figure and Figures 4-6 and 8 , periods of $30^{\circ} \mathrm{C}$ treatment are indicated (black bar) and temperature for the remaining time is $22^{\circ} \mathrm{C}$ (open bar). All single neurons in randomly selected fixed areas (see Materials and Methods) in the cultures were traced from phase-contrast micrographs in 3 successive days. In this figure and Figure 4, the cells were selected from these records to reflect the rough proportions of different cell types and morphological responses observed in the population. In $s h i^{i s t}$ cultures following the $30^{\circ} \mathrm{C}$ treatment, neurite initiation was greatly suppressed and retraction of neurites was seen in both monoand multipolar cells. In normal cultures, cells showed continuous neurite outgrowth throughout the $3 \mathrm{~d}$ period. varies with different degrees of differentiation, we traced the responses of neurons with respect to the initial neurite length. Cells were divided into 3 categories according to the initial length of their neurites ( $<10 \mu \mathrm{m}, 10-20 \mu \mathrm{m}$, and $>20 \mu \mathrm{m})$. The distributions of initial neurite lengths in normal and $s h t^{s S I}$ neurons were similar (Fig. 7, inset). In both normal and untreated $s h i^{i s t}$ cultures, less than a third of cells in each category reabsorbed their neurites during $24 \mathrm{hr}$ of incubation (Fig. 7). In contrast, shist cells incubated at $30^{\circ} \mathrm{C}$. showed a significantly higher percentage $(\sim 70 \%)$ of neurite reabsorption, regardless of the initial neurite length (Fig. 7). The remaining $s h i^{i s}$ cells which did not completely reabsorb their neurite invariantly showed a decrease in neurite length (see below). Therefore, the temperature-induced neurite reabsorption and retraction in $s h i^{i s t}$ neurons does not appear to depend on the extent of previous neurite outgrowth.

Neurite extension and retraction. The complete reabsorption of $s h i^{i s t}$ neurites may result from gradual retraction without compensating extension. This notion is consistent with the temperature effects on the length and growth rate of $s h i^{t s} 1$ neurites. Neurite growth rate as a function of culture age is calculated from the difference in length between successive days (Fig. 8). Neurons that completely reabsorbed their neurites in response to $30^{\circ} \mathrm{C}$ incubation were excluded from the analysis. Although there were fluctuations in the growth rates of neurites in all cultures, positive rates were always maintained except for $s h i^{i s t}$ cultures, which showed negative growth rates during exposure to $30^{\circ} \mathrm{C}$ (Fig. 8, d,e). The rate of neurite growth in $s h i^{i s l}$ neurons showed a rebound and was even accelerated upon returning to a permissive temperature (Fig. 8, compare $d$ to $a$ and $e$ to $b$ ). Most strikingly, the highest neuritic growth rate $(30.82 \mu \mathrm{m} / \mathrm{d})$ among all cultures occurred during the recovery period in the $s h i^{i s t}$ cultures exposed to $30^{\circ} \mathrm{C}$ in the first day of incubation (Fig. $8 d)$.

Arborization of shits1 neurons. Nerve cells in more than 30 different cultures were observed $1 \mathrm{~d}$ after seeding. SEM was employed to resolve fine branches of their arbors. In $s h i^{i s}$ and normal cultures kept at $22^{\circ} \mathrm{C}$ and in normal cultures exposed to $30^{\circ} \mathrm{C}$, the degree of neurite branching was similar. However, neurites of $s h i^{t s I}$ neurons exposed to $30^{\circ} \mathrm{C}$ for $8 \mathrm{hr}$ prior to fixation had fewer branches (Fig. 9). The histograms in Figure 10 further quantify the differences in branching patterns. The most prominent features of $s h i^{t s I}$ neurons following this temperature treatment were a complete absence of tertiary neurite branches and a higher percentage (about $65 \%$, as compared to about $15 \%$ in control cultures) of cells having only primary neurites. The tendency of neurites to branch was further quantified in terms of the number of secondary neurites in every $50 \mu \mathrm{m}$ of primary 

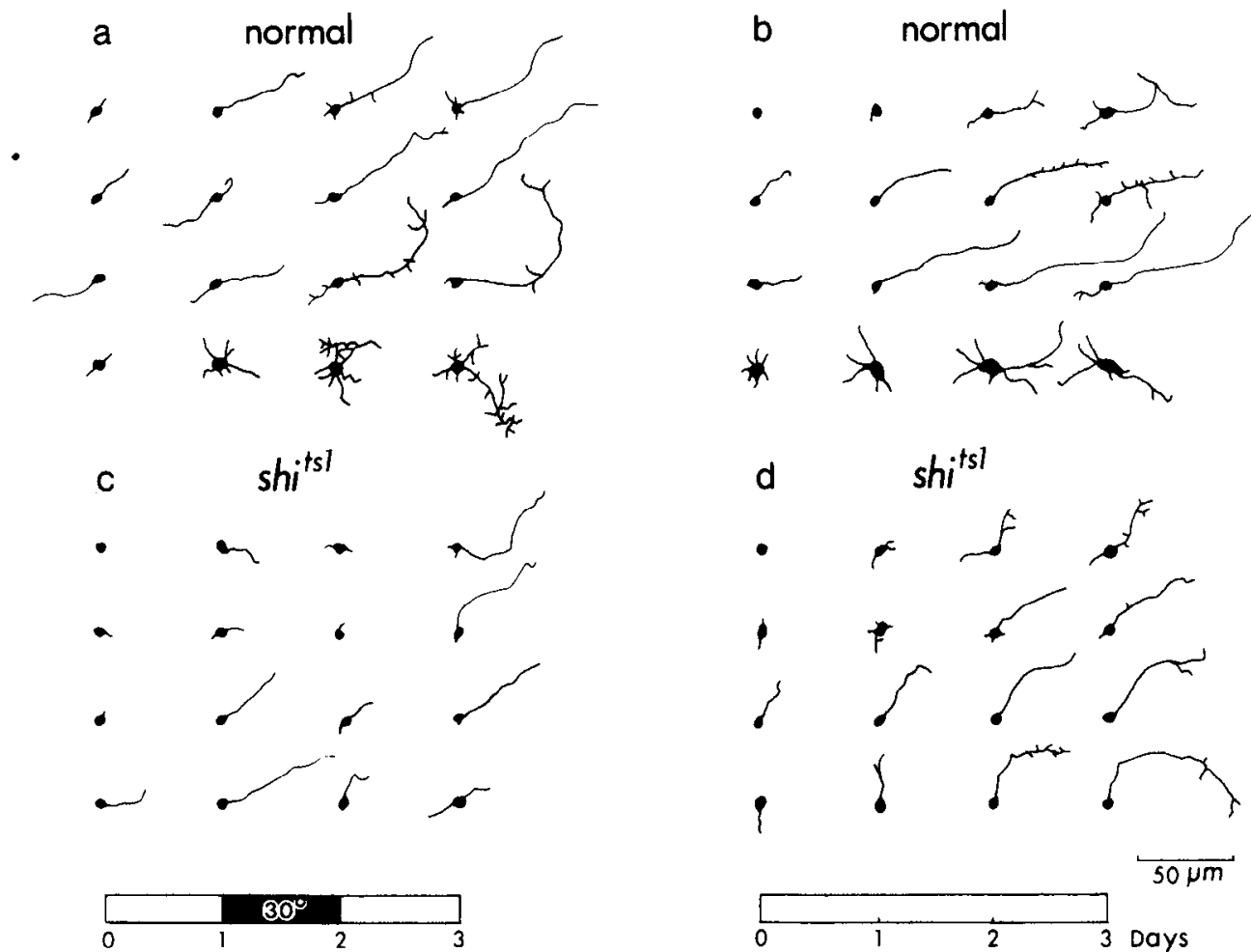

Figure 4. Examples of neuronal growth in normal and $s h i^{\text {ssl }}$ cultures with different temperature treatments. A decrease in neurite extension was detected in $s h i^{i s t}$ cells during the second day of incubation at $30^{\circ} \mathrm{C}$ (c). No suppression in neurite extension was observed in normal cultures under the same condition $(a)$. Without high-temperature treatment, continuous growth was maintained throughout the $3 \mathrm{~d}$ period in both normal $(h)$ and $s h i^{i s t}(d)$ cultures.

neurites and the number of tertiary neurites in $50 \mu \mathrm{m}$ of secondary neurites (Table 1). It can be seen that in $s h i^{i s l}$ cultures exposed to $30^{\circ} \mathrm{C}$, primary neurites branched fewer times and secondary neurites did not branch at all.

\section{Growth cone of shit $^{\text {ss } 1}$ neurons}

Growth cones play an important role in neurite extension and branching. For instance, growth cones with more microspikes (Haydon et al., 1985) and expansive lamellipodia (Argiro et al., 1984) sustain a greater rate of neurite elongation. Thus, the suppression in arborization (Fig. 9, Table 1) and negative growth rates (Fig. 8, $d, e$ ) of $s h i^{i s /}$ neurites at $30^{\circ} \mathrm{C}$ may be derived from defects in the growth cone.

Growth cone activity of $s h i^{i s t}$ neurons in 1-d-old culture was observed with phase-contrast microscopy. At $22^{\circ} \mathrm{C}$, shist and normal growth cones were similar (see Fig. 1). About $30 \%$ of neurons had growth cones with filopodia and lamellipodia which could be positively resolved with the Nikon phase-contrast optics. [It was later confirmed with the video contrast-enhancement system at high magnifications that, at any given time, only about $50 \%$ of neurons in culture were in their active phase, displaying growth cones (see Materials and Methods).] After exposure to $30^{\circ} \mathrm{C}$ for $4 \mathrm{hr}$, the frequency of neurons with distinct growth cones remained the same in normal cultures but was reduced to less than half in $s h i^{\text {sst }}$ cultures (see Table 2).

Growth cone morphology was further examined with SEM (Fig. 11). After the fixation and dehydration procedures, about $30 \%$ of the growth cones detectable with phase-contrast microscopy in the live preparation retained their morphology. Growth cones in normal cultures kept at 22 or $30^{\circ} \mathrm{C}$, as well as shist cultures grown at $22^{\circ} \mathrm{C}$, showed many filopodia, often $(\sim 50 \%)$ associated with veillike lamellipodia (Fig. 11). In $s h i^{i s I}$ cultures incubated at $30^{\circ} \mathrm{C}$ for $4 \mathrm{hr}$, very few growth conelike structures were detected at the tips of neurites $(<20 \%$ of those of control cultures). No growth cones exhibited lamellipodia, and only filopodia were occasionally observed (Fig. 11d).

\section{Adhesive properties of $\mathrm{sh}^{\mathrm{is}}$ neurons}

Attachment of the growth cone and portions of the cell body and neurites to the substratum critically influences the neuronal development. Inadequate adhesion results in retarded advancement of growth cones and the retraction of neurites (Letourneau, 1975, 1985; Johnston and Wessells, 1980; Bray, 1982).

We found that the adhesion of $s h i^{i s l}$ cells to the substratum depended on temperature. Dissociated neurons in suspension were incubated at $30^{\circ} \mathrm{C}$ for $30 \mathrm{~min}$ prior to plating. After plating, the culture was further maintained at $30^{\circ} \mathrm{C}$ for an additional 2 $\mathrm{hr}$ and the cell adhesion efficiency was determincd by scoring the density of cells with firmly attached somata. Unattached or incompletely attached cell bodies assumed a more spherical shape and vibrated upon gentle tapping on the microscope. At

\begin{tabular}{|c|c|c|c|c|}
\hline \multirow[b]{2}{*}{ Group } & \multirow[b]{2}{*}{$\begin{array}{l}\text { Tempera- } \\
\text { ture } \\
\left({ }^{\circ} \mathrm{C}\right)\end{array}$} & \multirow[b]{2}{*}{$\begin{array}{l}\text { Cells } \\
\text { examined } \\
(n)\end{array}$} & \multirow{2}{*}{$\begin{array}{l}\begin{array}{l}\text { Secondary } \\
\text { neurites }(n)\end{array} \\
50 \mu \mathrm{m} \\
\text { primary } \\
\text { neurite }\end{array}$} & \multirow{2}{*}{$\begin{array}{l}\text { Tertiary } \\
\text { neurites }(n) \\
50 \mu \mathrm{m} \\
\text { secondary } \\
\text { neurite }\end{array}$} \\
\hline & & & & \\
\hline \multirow[t]{2}{*}{ Normal } & 22 & 20 & 3.14 & 2.38 \\
\hline & 30 & 20 & 3.31 & 1.58 \\
\hline \multirow[t]{2}{*}{$s h i^{i s t}$} & 22 & 18 & 4.58 & 2.28 \\
\hline & 30 & 33 & 1.35 & 0 \\
\hline
\end{tabular}

The average number of secondary neurites in every $50 \mu \mathrm{m}$ of primary neurites and the average number of tertiary neurites in the same length of secondary neurites were measured from scanning electron micrographs. 


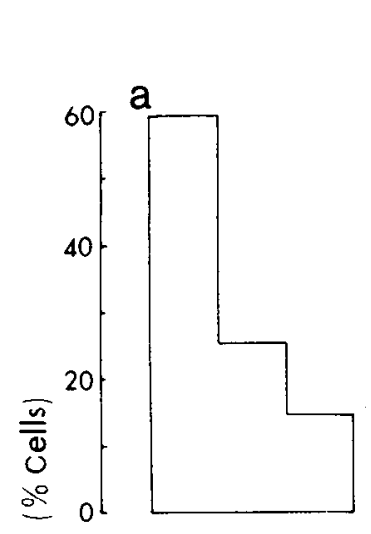

\section{normal}

b

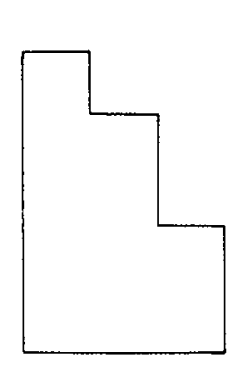

C
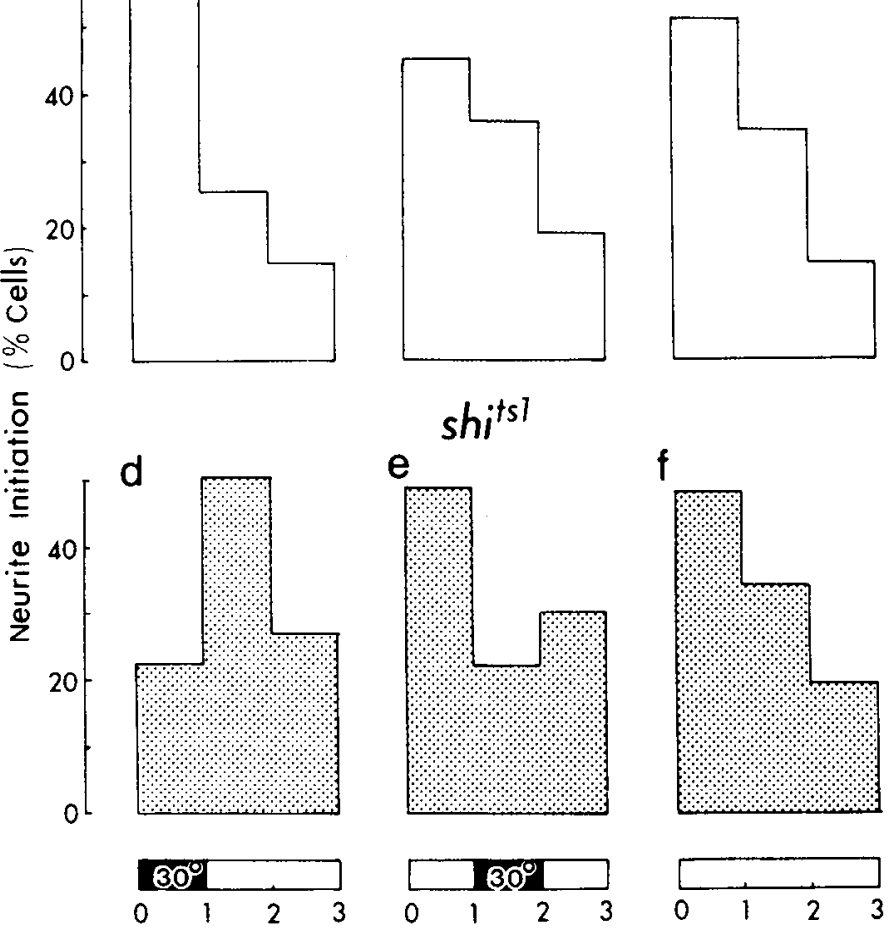

f

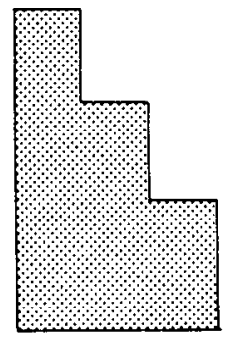

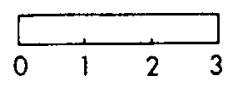

Figure 5. Effects of temperature shifts on neurite initiation. Open histograms represent data from normal neurons and stippled histograms from $s h i^{\text {ts }}$ neurons in this and the following figures. Neurons initially devoid of neurites that subsequently began neurite outgrowth were counted. Data include all neurons of this category in the fixed areas examined. Upshifts in temperature decreased the proportion of cells that initiated neurite outgrowth in $s h i^{i s l}(d, e)$ but not in normal cultures $(a, b)$. Data for control cultures are shown in $c$ and $f$. Note that after returning from high temperature there was a rebound in neurite initiation in $s h i^{t s i}$ cells $(d, e)$. Data were pooled from 4 normal and $5 s h i^{i s t}$ cultures. Each histogram was constructed from 126-252 cells.

$30^{\circ} \mathrm{C}$, the adhesion efficiency of $s h i^{i s l}$ cells was greatly reduced, to one-third of that at $22^{\circ} \mathrm{C}$ (Table 3 ). Correspondingly, there was an increase in the number of cells that were not firmly attached to the substratum (data not shown). In contrast, the adhesion efficiency of normal cells was even increased at $30^{\circ} \mathrm{C}$ (1.31 times of that at $22^{\circ} \mathrm{C}$; see Table 3 ).

It should be noted that, in addition to the cell body, $s h i^{i s I}$

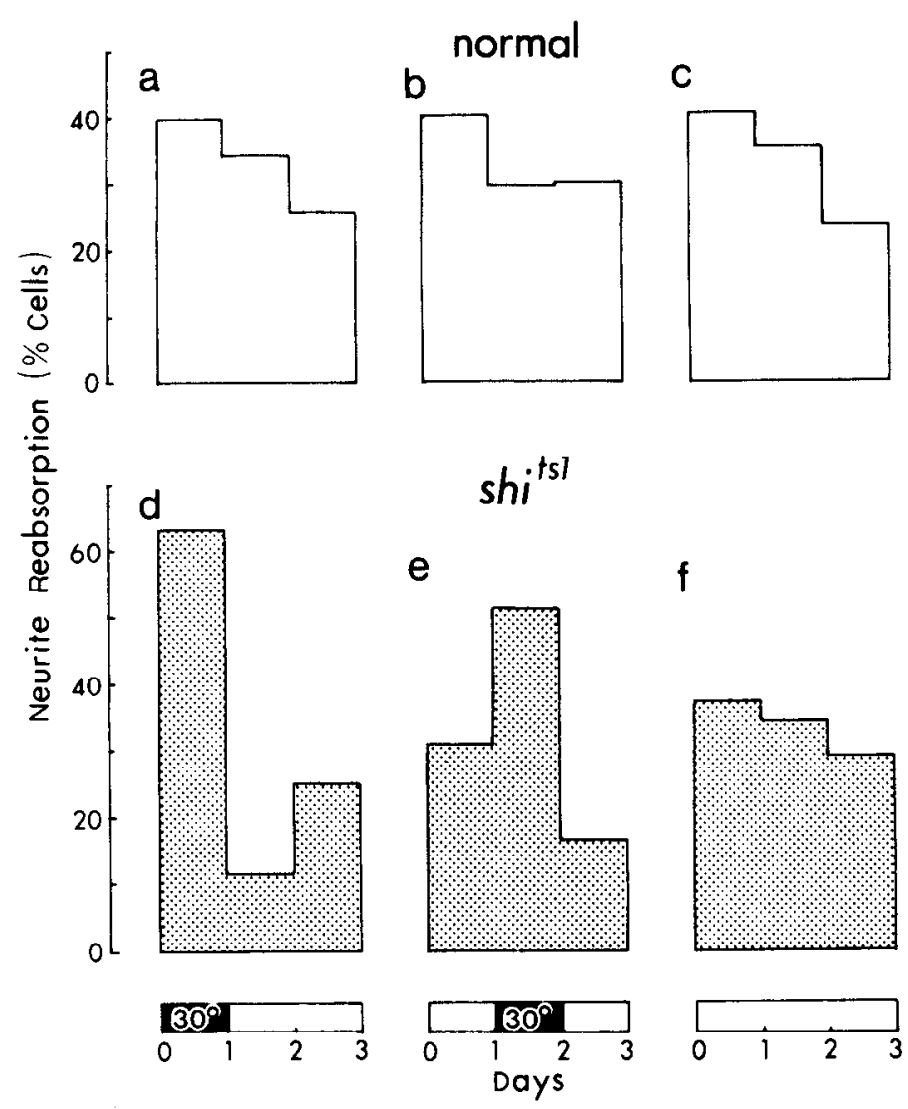

Figure 6. Effects of high temperature on neurite reabsorption. The percentage of cells that completely reabsorbed their neurites were scored on 3 consecutive days. Exposure to high temperature increased the proportion of cells with neurite reabsorption in $s h i^{s I}$ cultures $(d, e)$ but not in normal cultures $(a, b)$. Results of control cultures are shown in $c$ and $f$. Data were pooled from 4 normal and $5 s h i^{i s t}$ cultures. Each histogram was based on a sample of 203-386 cells.

neurites also showed poor adhesion to the substratum at $30^{\circ} \mathrm{C}$. At $2 \mathrm{hr}$ after plating, neurites of some cells were not attached to the substratum even though their cell bodies were well anchored. At $30^{\circ} \mathrm{C}$, more than $70 \%$ of attached cells in $s h i^{i s i}$ cultures displayed unanchored neurites as compared with less than $20 \%$ of cells in normal cultures.

Therefore, these experiments demonstrated that the $s h i^{i s t}$ mutation affects neuronal membrane adhesion properties. Regulation of this basic membrane property may be associated with the defective membrane fusion and retrieval mechanisms previously reported.

Table 2. Frequencies of neurons exhibiting distinct growth cones in normal and $s h i^{\text {st }}$ cultures

\begin{tabular}{llllll} 
Group & $\begin{array}{l}\text { Temperature } \\
\left({ }^{\circ} \mathrm{C}\right)\end{array}$ & $\begin{array}{l}\text { Number of } \\
\text { experiments }\end{array}$ & $\begin{array}{l}\text { Total cells } \\
\text { examined }(n)\end{array}$ & $\begin{array}{l}\text { Total cells } \\
\text { with growth } \\
\text { cones }(n)\end{array}$ & $\begin{array}{l}\text { Frequency } \\
(\%)\end{array}$ \\
\hline Normal & 22 & 3 & 245 & 74 & $29.49 \pm 5.52$ \\
& 30 & 3 & 222 & 70 & $30.86 \pm 6.83$ \\
shitst & 22 & 3 & 311 & 101 & $32.16 \pm 6.65$ \\
& 30 & 3 & 270 & 36 & $13.53 \pm 4.06$
\end{tabular}

Errors in the frequencies are SDs derived from 3 independent experiments, each including 56-125 cells. Growth cones were detected with the phase-contrast optics (Nikon Diaphot microscope, $40 \times, 0.55$ N.A. objective). For each experiment, the ccll suspension was cqually divided and plated on uncoated coverslips and was grown for $1 \mathrm{~d}$ at $22^{\circ} \mathrm{C}$. Afterwards, experimental cultures were incubated at $30^{\circ} \mathrm{C}$ for $4 \mathrm{hr}$ prior to observation. See text for explanation. 


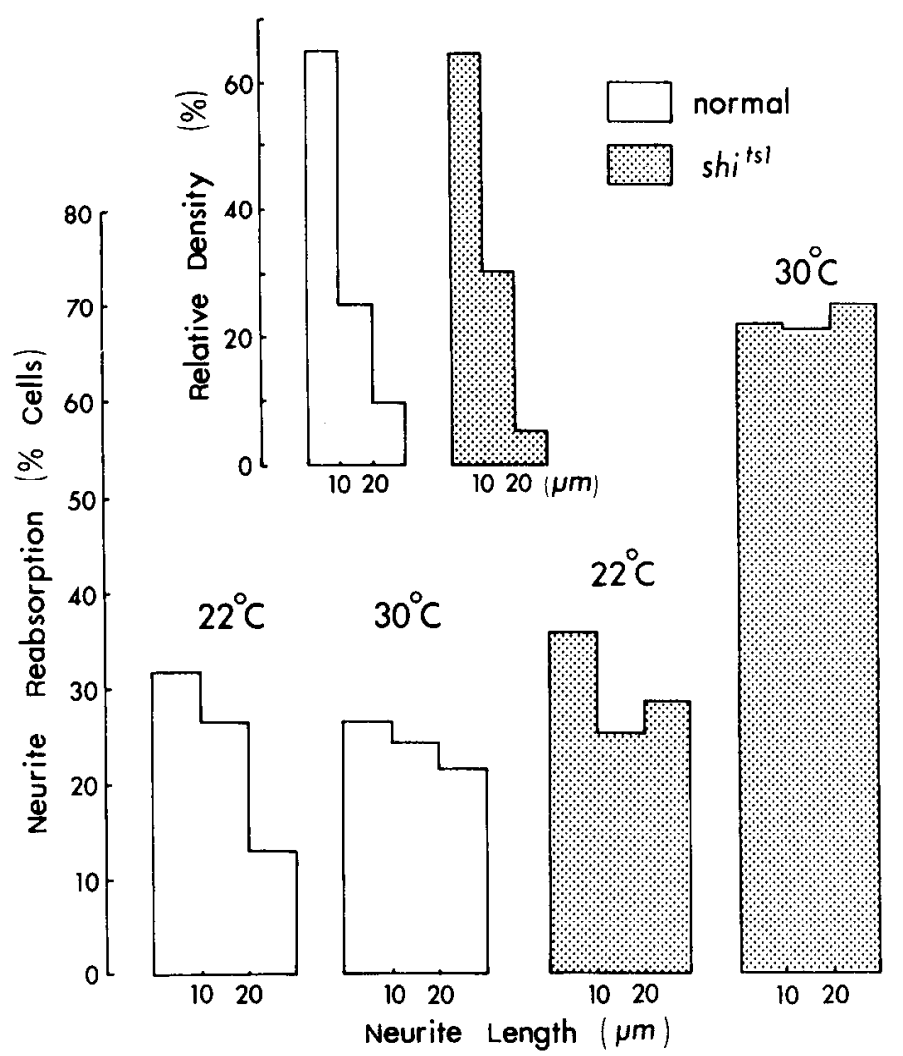

Figure 7. Frequency of neurite reabsorption as a function of initial neurite lengths. Only the longest primary neurites were scored and cells were classified by their lengths. The initial distributions of neurite lengths in normal and $s h i^{i s}$ neurons were similar immediately after plating (inset). The percentages of cells that completely reabsorbed all neurites following $1 \mathrm{~d}$ incubation at 22 or $30^{\circ} \mathrm{C}$ are shown in the lower histograms. Note that a large proportion $(\sim 70 \%)$ of cells in $s h i^{i s t}$ cultures exposed to $30^{\circ} \mathrm{C}$ reabsorbed their neurites regardless of the initial neuritic lengths. In comparison, in normal cultures, as well as the untreated $s h i^{i s t}$ cultures, only $15-35 \%$ of cells reabsorbed their neurites in the same periods. For each histogram, data were pooled from 574-933 cells.

\section{Discussion}

\section{Morphology of shisi neurons in culture}

As reviewed in the introduction, manifestations of a defective membrane recycling mechanism in various $s h i^{i s l}$ cell types include (1) the depletion of intracellular vesicles coupled with an increase in cisternaelike structures, possibly due to vesicle fusion, and (2) an increase in pitlike structures and fingerlike invaginations on the plasma membrane, presumably associated with a disrupted membrane pinch-off mechanism (Kosaka and Ikeda, 1983a, b). As a result, endocytosis and synaptic transmission are blocked and the differentiation of nerve, muscle and epithelial structures is disrupted.

Our study was intended to examine isolated $s h i^{i s t}$ neurons in culture and to analyze the possible relationship between the membrane recycling mechanism and ncuronal development. We found striking changes in growth cone formation and a weakened cell adhesion in these neurons at $30^{\circ} \mathrm{C}$. Our results provide a new line of evidence supporting the view that growth cone activities are closely associated with neurite extension and branching (Letourneau, 1975; Johnston and Wessells, 1980).

Profound alterations in the morphological development of $s h i^{i s t}$ neurons that were induced by high-temperature treatment include (1) reversible suppression of neurite initiation, (2) grad-

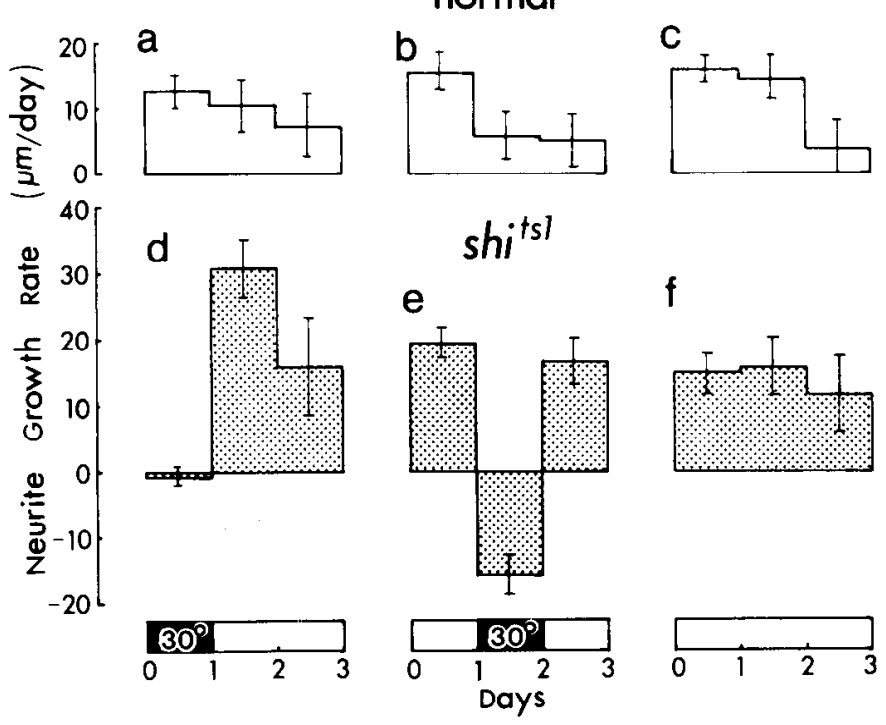

Figure 8. Changes in growth rate in response to temperature treatments. The longest primary neurites were identified and followed in 3 successive days. Growth rate is shown as the change in neurite length per day. Positive growth rates were always maintained in normal cultures regardless of temperature $(a-c)$. The same was true for $s h{ }^{i s l}$ cultures maintained at room temperature $(f)$. Negative growth rate, reflecting neurite retraction over initiation and elongation, were detected only in $s h t^{i s t}$ cultures during incubation at $30^{\circ} \mathrm{C}(d$ and $e)$. Note the rebound in growth rate upon returning to $22^{\circ} \mathrm{C}(d$ and $e)$. Neurons that degenerated during the course of observation were excluded from the analysis. Error bars indicate SEM based on 26-70 cells.

ual retraction of neurites reflected by a negative growth rate, (3) abrupt neurite reabsorption, and (4) inhibition of arborization. Analysis of each of these components of neurite outgrowth may provide important clues to the relationships between the highly dynamic process of membrane recycling and the generation and maintenance of neuronal forms.

\section{Growth cone formation}

The growth cone consists of a protoplasmic enlargement at the tip of growing neurites that contains mostly membranous organelles and cytoskeletal elements and of thin peripheral regions that are composed of motile filopodia and lamellipodia (Ya-

Table 3. Temperature effects on cell adhesion as determined by plating efficiency

\begin{tabular}{lllll} 
Group & $\begin{array}{l}\text { Tempera- } \\
\text { ture } \\
\left({ }^{\circ} \mathrm{C}\right)\end{array}$ & $\begin{array}{l}\text { Number } \\
\text { of ex- } \\
\text { periments }\end{array}$ & $\begin{array}{l}\text { Total cells } \\
\text { attached } \\
(n)\end{array}$ & $\begin{array}{l}\text { Plating effi- } \\
\text { ciency at } 30^{\circ} \mathrm{C} \\
\text { normalized } \\
\text { to } 22^{\circ} \mathrm{C}\end{array}$ \\
\hline Normal & 22 & 5 & 1218 & $1.31 \pm 0.23$ \\
& 30 & 5 & 1521 & \\
shits & 22 & 5 & 1656 & $0.34 \pm 0.03$ \\
& 30 & 537 &
\end{tabular}

For each experiment, the dissociated cell suspension was equally divided for incubation at 22 or $30^{\circ} \mathrm{C}$ for $30 \mathrm{~min}$ prior to plating onto poly(L-lysine)-coated coverslips. For each culture, the number of cells attached on the substratum in $1.452 \mathrm{~mm}^{2}$ area was scored. Plating efficiency at $30^{\circ} \mathrm{C}$ is normalized to that of $22^{\circ} \mathrm{C}$, i.e., No. of cells attached at $30^{\circ} \mathrm{C} / \mathrm{No}$. of cells attached at $22^{\circ} \mathrm{C}$. Errors represent SD of the normalized values. Student's $t$ test indicates that the $30^{\circ} \mathrm{C}$ treatment significantly decreased the plating efficiency of $s i^{i s l}$ cells $(p \ll 0.001)$ but significantly increased that of normal cells $(p<0.05)$. 
Figure 9. Scanning electron micrographs showing neurite branching. $a$, Normal neuron at $22^{\circ} \mathrm{C}$. $b$, Normal neuron at $30^{\circ} \mathrm{C}$. c, shist neuron at $22^{\circ} \mathrm{C}$. $d$, shitsl neuron at $30^{\circ} \mathrm{C}$. Scale bar, 10 $\mu \mathrm{m}$.
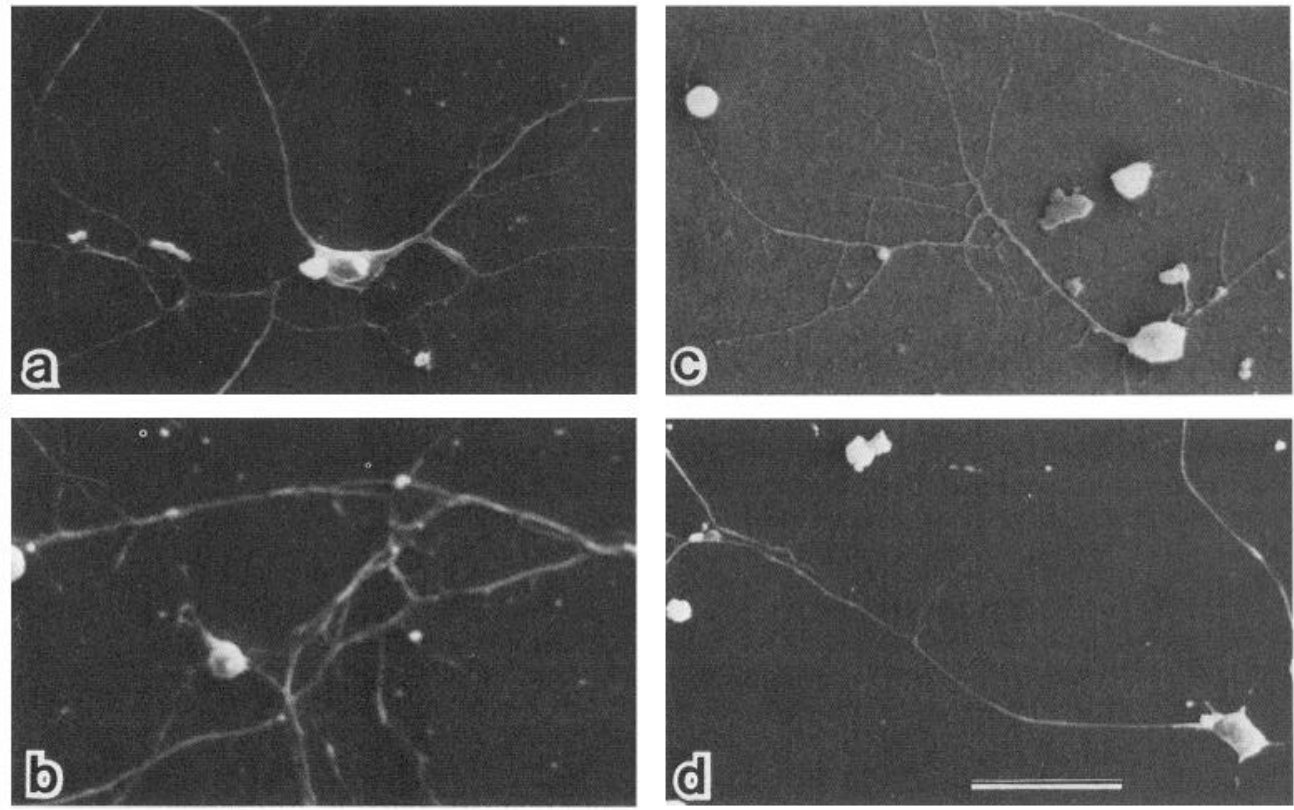

normal

$22^{\circ} \mathrm{C}$

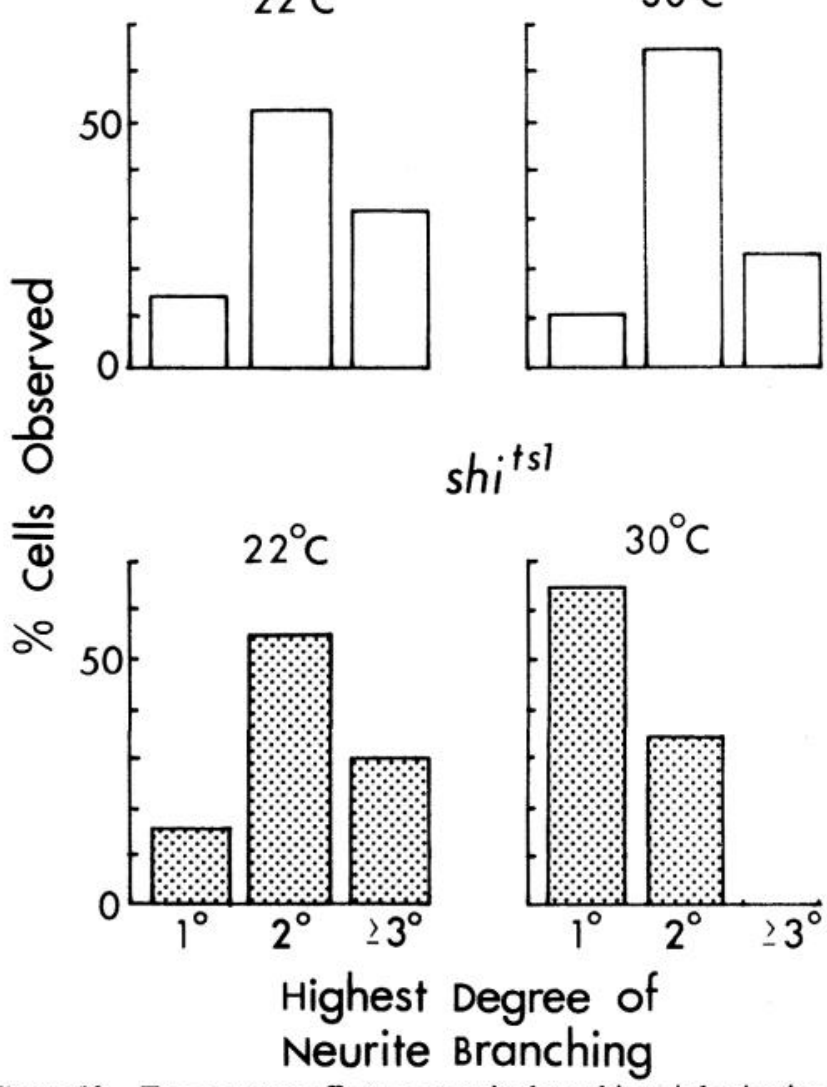

Figure 10. Temperature effects on neurite branching. Arborization of individual normal and $s h i^{i s t}$ neurons in scanning electron micrographs were analyzed. Histograms represent the distribution of neurons with the primary $\left(1^{\circ}\right)$, secondary $\left(2^{\circ}\right)$, and tertiary or higher $\left(\geqq 3^{\circ}\right)$ neurites as the highest degree of branching. No difference in neurite arborization was detected between normal and $s h i^{i s l}$ neurons at $22^{\circ} \mathrm{C}$. The same pattern of neurite branching was seen in normal cultures at $30^{\circ} \mathrm{C}$. Note the complete absence of tertiary branches and a higher percentage of cells with exclusively primary neurites in $s h i^{i s l}$ culture at $30^{\circ} \mathrm{C}$. Data were collected from 34-71 single neurons. mada et al., 1971; Landis, 1983). Although there has been a demonstration of neurite elongation on sufficiently adhesive substratum without filopodia or lamellipodia (Marsh and Letourneau, 1984), it is generally accepted that under normal conditions projection and retraction of growth cones lead to elongation (Yamada et al., 1971; Johnston and Wessells, 1980; Letourneau, 1985) and branching (Bray, 1973a) of neurites.

As previously reported, the marker particles on the surface of growing axons (Bray, 1970) and branch points of neurons (Bray, 1973a) in culture remained at a fixed distance from the cell body as the growth cone progressed a substantial distance. It is thought that membrane incorporation and retrieval occur mainly at the growth cone rather than on the existing neurites (Bray, 1970, 1973b; Landis, 1983). The leading edge of growth cones have been shown to be much more active than axons in the process of endocytosis (Bray, 1973b; Bunge, 1977) and in the assembly of microtubules (Bamburg et al., 1986). Microtubules constitute a major longitudinal structure of axons and are thought to be responsible for membrane vesicle transport.

High-temperature treatments of $s h i^{t s l}$ neurons induced striking alterations in growth cone formation before changes in the branching pattern of existing neurites could be detected. Although there have been no direct ultrastructural observations on membrane recycling in $s h i^{i s t}$ growth cones, it is likely that the same membrane defect observed in a wide variety of cell types and in other regions of neurons (see introduction) also exists in the mutant growth cone. Therefore, our results are consistent with the hypothesis raised by previous studies in other species that the growth cone is very actively engaged in membrane incorporation and retrieval to regulate its plasma membrane area.

\section{Membrane adhesion properties}

From previous studies, it is clear that growth cone morphology critically depends on the adhesion of lamellipodia and filopodia to the substratum (Letourneau, 1975, 1985). In principle, besides the change in the membrane surface area, active growth cones require constant shifting of adhesion sites in contact with 

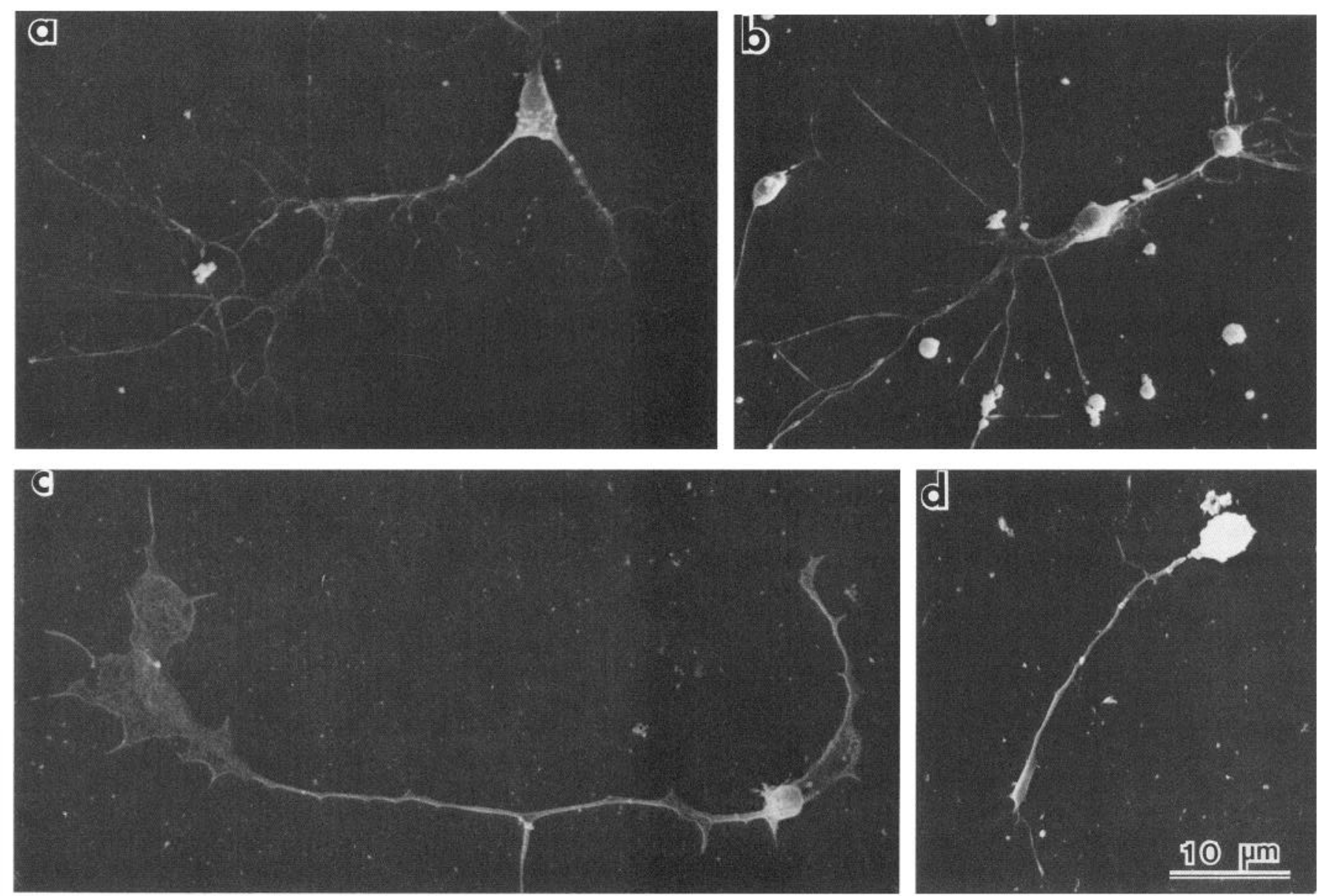

Figure 11. Growth cones of cultured neurons in SEM. a, Normal at $22^{\circ} \mathrm{C}$. b, Normal at $30^{\circ} \mathrm{C}$. c, shi $i^{i s t}$ at $22^{\circ} \mathrm{C} . d, s h i^{i s t}$ at $30^{\circ} \mathrm{C}$.

the substratum. As the lamellipodia ruffle and filopodia extend and retract, new adhesive sites in some areas must be established, while old sites in other areas must be broken. This process presumably involves redistribution within the growth cone membrane of the molecular components responsible for adhesion. The redistribution can be achieved by insertion and pinchoff of membrane vesicles or by lateral movements of membrane adhesion components.

As described in Results, shitsl cell bodies (Table 3) and neurites exhibited poor adhesion to the substratum. Apparently, the weakened adhesion is widespread in different neuronal regions, such as adhesive sites along neurites and within growth cones. Our observations on $s h i^{i s l}$ growth cones raise the possibility that a membrane recycling mechanism is involved in the incorporation and retrieval of membrane molecular components responsible for growth cone adhesion. Within $4 \mathrm{hr}$ of exposure to $30^{\circ} \mathrm{C}$, the number of growth cones in $s h i^{t s I}$ cultures dramatically decreased (Table 2). With the SEM, the remaining growth cones showed poor morphology, lacking any lamellipodia; this is an indication of weakened adhesion to the substratum. In contrast, growth cones in control cultures withstood the fixation and dehydration procedures, displaying extended filopodia and lamellipodia (Fig. 11, a-c). At high temperature, $s h i^{t s I}$ growth cones did not remain static and retained a normal appearance but showed signs of disintegration (Fig. 11d and unpublished results from video contrast-enhancement observations). This indicates that the membrane defect in $s h i^{i s l}$ neurons does not simply stop the regulation of surface area but also affects its adhesive properties.

\section{Mechanisms of altered membrane recycling in shi $^{\text {tsl }}$ cells}

The molecular mechanism of the $s h i^{i s t}$ defect still remains unknown, and many possibilities exist to explain the membrane recycling block in $s h i^{t s i}$ cells. According to our results, however, a simple block in the synthesis of membrane components is not a likely explanation. The observations of a rebound in neurite initiation (Fig. 5) and a higher than normal rate of neurite growth in $s h i^{i s t}$ cultures upon returning to permissive temperature (Fig. $8 d$ ) suggest that neither the total membrane pool nor the primary process of membrane synthesis was altered. The rebound in growth rate might have resulted from the blockage in the incorporation of newly synthesized membrane components into the growing tip during $30^{\circ} \mathrm{C}$ incubation.

Several other mechanisms that can account for the $s h i^{i s l} \mathrm{de}$ fects still remain to be fully investigated. (1) Integration of intracellular membrane, possibly vesicles, into plasma membrane is blocked at $30^{\circ} \mathrm{C}$. (2) Membrane integration and fusion with the plasma membrane are not affected, but the inserted vesicle membrane fails to expand. (3) A block occurs in the pinch-off mechanism of the plasma membrane and internal tubular membrane. (4) Alternatively, the $s h i^{i s l}$ gene product could be important to a common mechanism underlying all of the above 
processes. (5) Associated with these possibilities, a defect in the regulation of cytoskeletal elements must be considered.

Certain cytoskeletal components are thought to be responsible for the initiation, extension, and branching of neurites as well as the movements of growth cones (Letourneau and Ressler, 1984; Marsh and Letourneau, 1984; Bunge, 1986; Letourneau et al., 1986). For example, treatment of neurons with cytochalasin $\mathrm{B}$, which disrupts microfilament function, causes microspikes to retract and growth cones to round up (Yamada et al., 1971; Marsh and Letourneau, 1984; for a review, see Landis, 1983). In addition, it is known that microtubules propel membrane vesicles from their site of synthesis in the cell body to the growth cone (Bray, 1973b). Microtubules are also required for the maintenance of neurites (Letourneau, 1985; Bunge, 1986). Other cytoskclcton-associatcd protcins such as vinculin (Scfton et al., 1981), large complexes called SAMs (Edelman, 1984), and membrane surface components like adherons (Schubert and LaCorbiere, 1985) have also been implicated in cell adhesion mechanisms.

Biochemical studies of $s h i^{t s t}$ nerve and muscle proteins have been initiated. So far, our preliminary results of SDS gel electrophoresis have indicated no qualitative changes of the major cytoskeletal proteins. In 2-dimensional gel analysis, no changes in migration rate have been detected in $\alpha$-actinin, actin, myosin, $\alpha$ - and $\beta$-tubulin, and tropomyosin (J.J.-C. Lin, Y.-T. Kim, and C.-F. Wu, unpublished observations). However, we cannot exclude the possibility that there is a subtle change in these proteins that is not readily detectable in SDS gel electrophoresis or that the $s h i^{i s t}$ defect is related to a minor regulatory protein.

Intracellular free $\mathrm{Ca}^{2+}$ is thought to be important in regulating membrane fusion and cytoskeletal elements. $\mathrm{Ca}^{2+}$ action potentials supported by a high density of $\mathrm{Ca}^{2+}$ channels in growth cones have been demonstrated in cultured neurons (Anglister et al., 1982). Recently, it was suggested that $\mathrm{Ca}^{2+}$ influx induces retraction of growth cones (Cohan et al., 1986). Therefore, a possibility exists that intracellular free $\mathrm{Ca}^{2+}$ concentration in $s h i^{t s}$ may be increased at the restrictive temperature. Nevertheless, $\mathrm{Ca}^{2+}$ influx in both adult and larval $s h i^{i s t}$ muscles are not apparently altered by high temperature since their $\mathrm{Ca}^{2+}$ action potentials appear normal (Ikeda et al., 1976; C.-F. Wu, unpublished observations). Furthermore, the muscle membrane excitability in $s h i^{i s t}$ is not altered at the restrictive temperature. Therefore, an increase in intracellular free $\mathrm{Ca}^{2+}$ due to release from internal storage is also not likely, otherwise it would increase the $\mathrm{Ca}^{2+}$-dependent $\mathrm{K}^{+}$current which can suppress the generation of action potentials in muscle (Elkins et al., 1986; Singh et al., 1986).

These hypothetical mechanisms of the $s h i^{i s l}$ defect should be investigated by using additional techniques such as immunocytochemistry and ultrastructural examinations. Further studies of the $s h i^{t^{s}}$ gene product will not only provide insights into how membrane fusion, adhesion, and endocytosis regulate neuronal morphology but may also extend our knowledge of these important cellular processes.

\section{References}

Anglister, L., I. C. Farber, A. Shahar, and A. Grinvald (1982) Localization of voltage-sensitive calcium channels along developing neurites: Their possible role in regulating neurite elongation. Dev. Biol. 94: 351-365.

Argiro, V., M. B. Bunge, and M. I. Johnson (1984) Correlation between growth form and movement and their dependence on neuronal age. J. Neurosci. 4: 3051-3062.
Bamburg, J. R., D. Bray, and K. Chapman (1986) Assembly of microtubules at the tip of growing axons. Nature 321: 788-790.

Banker, G. A., and W. Cowan (1977) Rat hippocampal neurons in dispersed cell culture. Brain Res. 126: 397-425.

Benzer, S. (1973) Genetic dissection of behavior. Sci. Am. 229(6): 24 37.

Bray, D. (1970) Surface movements during the growth of single explanted neurons. Proc. Natl. Acad. Sci. USA 65: 905-910.

Bray, D. (1973a) Branching patterns of individual sympathetic neurons in culture. J. Cell Biol. 56: 702-712.

Bray, D. (1973b) Model for membrane movements in the neural growth cone. Nature 244: 93-96.

Bray, D. (1982) Filopodial contraction and growth cone guidance. In Cell Behavior, R. Bellairs, A. Curtis, and G. Dunn, eds., pp. 299-317, Cambridge University Press, London.

Bunge, M. B. (1977) Initial endocytosis of peroxidase or ferritin by growth cones of cultured nerve cells. J. Neurocytol. 6: 407-439.

Bunge, M. B. (1986) The axonal cytoskeleton: Its role in generating and maintaining cell form. Trends Neurosci. 9: 477-482.

Buzin, C. H., S. A. Dewhurst, and R. L. Seecof (1978) Temperaturesensitivity of muscle and neuron differentiation in embryonic cell

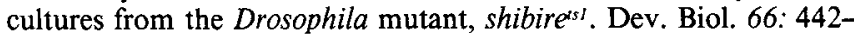
456.

Cohan, C. S., J. A. Connor, and S. B. Kater (1986) Signals which inhibit growth cone motility also increase intracellular calcium levels within the growth cone. Soc. Neurosci. Abstr. 12: 370.

Costello, W. J., and L. Salkoff (1983) Induced reduction in fiber number of indirect flight muscles in the Drosophila mutant shibire. Soc. Neurosci. Abstr. 9: 832.

Costello, W. J., and L. Salkoff (1986) Suppression of the membrane defect by divalent cations in the Drosophila mutant shibire. J. Neurosci. 6: $3634-3639$

Edelman, G. M. (1984) Modulation of cell adhesion during induction, histogenesis, and perinatal development of the nervous system. Annu. Rev. Neurosci. 7: 339-377.

Elkins, T., B. Ganetzky, and C.-F. Wu (1986) A Drosophila mutation that eliminates a calcium-dependent potassium current. Proc. Natl. Acad. Sci. USA 83: 8415-8419.

Ganetzky, B., and C.-F. Wu (1985) Genes and membrane excitability in Drosophila. Trends Neurosci. 8: 322-326.

Grigliatti, T. A., L. Hall, R. Rosenbluth, and D. T. Suzuki (1973) Temperature-sensitive mutation in Drosophila melanogaster. XIV. A selection of immobile adults. Mol. Gen. Genet. 120: 107-114.

Hall, J. C. (1982) Genetics of the nervous system in Drosophila. Q. Rev. Biophys. 15: 223-479.

Haydon, P. G., C. S. Cohan, D. P. McCobb, H. R. Miller, and S. B. Kater (1985) Neuron-specific growth cone properties as seen in identified neurons of Helisoma. J. Neurosci. Res. 13: 135-147.

Hummon, M. R., and W. J. Costello (1984) Induced alteration in the development of the Drosophila giant fiber pathway in the temperaturesensitive mutant shibire. Soc. Neurosci. Abstr. 10: 1032.

Hummon, M. R., and W. J. Costello (1987) Induced disruption in the connectivity of an identified neuron in the Drosophila ts mutant shibire. J. Neurosci. (in press).

Ikeda, K., S. Ozawa, and S. Hagiwara (1976) Synaptic transmission reversibly conditioned by single-gene mutation in Drosophila melanogaster. Nature 259: 489-491.

Johnston, R. N., and N. K. Wessells (1980) Regulation of the elongating nerve fiber. Curr. Top. Dev. Biol. 16: 165-206.

Kelly, L. E., and D. T. Suzuki (1974) The effect of increased temperature on electroretinograms of temperature-sensitive paralysis mutants of Drosophila melanogaster. Proc. Natl. Acad. Sci. USA 71: 4906-4909.

Kim, Y.-T., and C.-F. Wu (1986) Effects of altered membrane recycling process on neuronal development: Analysis of cultured neurons of the Drosophila mutant, shibirest. Soc. Neurosci. Abstr. 12: 1212.

Koenig, J. H., and K. Ikeda (1983) Evidence for a presynaptic blockage of transmission in a temperature-sensitive mutant of Drosophila. J. Neurobiol. 14: 411-419.

Koenig, J. H., K. Saito, and K. Ikeda (1983) Reversible control of synaptic transmission in a single gene mutant of Drosophila melanogaster. J. Cell Biol. 96: 1517-1522.

Kosaka, T., and K. Ikeda (1983a) Possible temperature-dependent blockage of synaptic vesicle recycling induced by a single-gene mutation in Drosophila. J. Neurobiol. 14: 207-225.

Kosaka, T., and K. Ikeda (1983b) Reversible blockage of membrane 
retrieval and endocytosis in the garland cell of the temperature-sensitive mutant of Drosophila melanogaster, shibirest. J. Cell Biol. 97 . 499-507.

Kulkarni, B., and A. Padhye (1982) Temperature-sensitive paralytic mutations on the second and third chromosomes of Drosophila melanogaster. Genet. Res. Camb. 40: 191-199.

Landis, S. C. (1983) Neuronal growth cones. Annu. Rev. Physiol. 45. 567-580.

Lctourneau, P. C. (1975) Possible roles for ccll-to-substratum adhcsion in neuronal morphogenesis. Dev. Biol. 44: 77-91.

Letourneau, P. C. (1985) Axonal growth and guidance. In Molecular Bases of Neural Development, G. M. Edelman, W. E. Gall, and W. M. Cowan, eds., pp. 269-293, Wiley, New York.

Letourneau, P. C., and A. H. Ressler (1984) Inhibition of neurite initiation and growth by taxol. J. Cell Biol. 98: 1355-1362.

Letourneau, P. C., T. A. Shattuck, and A. H. Ressler (1986) Branching of sensory and sympathetic neurites in vitro is inhibited by treatment with taxol. J. Neurosci. 6: 1912-1917.

Marsh, L., and P. C. Letourneau (1984) Growth of neurites without filopodial or lamellipodial activity in the presence of cytochalasin B. J. Cell Biol. 99: 2041-2047.

Nation, J. L. (1983) A new method using hexamethyldisilazane for preparation of soft insect tissues for scanning clcctron microscopy. Stain Technol. 58: 347-351.

Poodry, C. A., and L. Edgar (1979) Reversible alteration in the neuromuscular junctions of Drosophila melanogaster bearing a temperature-sensitive mutation, shibire. J. Cell Biol. 81: 520-527.

Poodry, C. A., L. Hall, and D. T. Suzuki (1973) Developmental properties of shibiress: A pleiotropic mutation affecting larval and adult locomotion and development. Dev. Biol. 32: 373-386.

Schneider, I., and A. B. Blumenthal (1978) Drosophila cell and tissue culture. In The Genetics and Biology of Drosophila, Vol. IIa, M. Ashburner and T. R. F. Wright, eds., pp. 265-315, Academic, New York.

Schubert, D., and M. LaCorbiere (1985) Isolation of an adhesionmediating protein from chick neural retina adherons. J. Cell Biol. 101: $1071-1077$.
Sefton, B. M., T. Hunter, E. H. Ball, and S. J. Singer (1981) Vinculin: A cytoskeletal target of the transforming protein of Rous sarcoma virus. Cell 24: 165-174.

Siddiqi, O., and S. Benzer (1976) Neurophysiological defects in temperature-sensitive paralytic mutants of Drosophila melanogaster. Proc. Natl. Acad. Sci. USA 77: 3253-3257.

Singh, S., and O. Siddiqi (1981) torpid a new sex-linked paralytic mutation in Drosophila melanogaster. Mol. Gen. Genet. 181: 400402.

Singh, S., C.-F. Wu, and B. Ganetzky (1986) Interactions among different $\mathrm{K}^{+}$and $\mathrm{Ca}^{++}$currents in normal and mutant Drosophila larval muscles. Soc. Neurosci. Abstr. 12: 559.

Suzuki, D. T. (1974) Behavior in Drosophila melanogaster. A geneticist's view. Can. J. Genet. Cytol. 16: 713-735.

White, K., and D. R. Kankel (1978) Patterns of cell division and cell movement in the formation of the imaginal nervous system in Drosophila melanogaster. Dev. Biol. 65: 296-321.

Wolosewick, J. J., and K. R. Porter (1979) Preparation of cultured cells for electron microscopy. In Practical Tissue Culture Applications, K. Maramorosch and H. Hirumi, eds., pp. 59-85, Academic, New York.

Wu, C.-F., B. Ganetzky, L. Y. Jan, Y.-N. Jan, and S. Benzer (1978) A Drosophila mutant with a tcmperature-sensitive block in nerve conduction. Proc. Natl. Acad. Sci. USA 75: 4047-4051.

Wu, C.-F., J. M. Berneking, and D. L. Barker (1983a) Acetylcholine synthesis and accumulation in the CNS of Drosophila larvae: Analysis of shibiress, a mutant with a temperature-sensitive block in synaptic transmission. J. Neurochem. 40: 1386-1396.

Wu, C.-F., N. Suzuki, and M.-M. Poo (1983b) Dissociated neurons from normal and mutant Drosophila larval central nervous system in cell culture. J. Neurosci. 3: 1888-1899.

Yamada, K. M., B. S. Spooner, and N. K. Wessells (1971) Ultrastructure and function of growth cones and axons of cultured nerve cells. J. Cell Biol. 49: 614-635. 